\title{
Prognostic factors for survival and radiation necrosis after stereotactic radiosurgery alone or in combination with whole brain radiation therapy for 1-3 cerebral metastases
}

Lars Hendrik Schüttrumpf ${ }^{1 \dagger}$, Maximilian Niyazi ${ }^{1 \dagger}$, Silke Birgit Nachbichler ${ }^{1}$, Farkhad Manapov ${ }^{1}$, Nathalie Jansen ${ }^{2}$, Axel Siefert ${ }^{3}$ and Claus Belka ${ }^{1 *}$

\begin{abstract}
Background: In the present study factors affecting survival and toxicity in cerebral metastasized patients treated with stereotactic radiosurgery (SRS) were analyzed with special focus on radiation necrosis.

Patients and methods: 340 patients with 1-3 cerebral metastases having been treated with SRS were retrospectively analyzed. Radiation necrosis was diagnosed by MRI und PET imaging. Univariate and multivariate analysis using a Cox proportional hazards regression model and log-rank test were performed to determine the prognostic value of treatment-related and individual factors for outcome and SRS-related complications.
\end{abstract}

Results: Median overall survival was 282 days and median follow-up 721 days. 44\% of patients received WBRT during the course of disease. Concerning univariate analysis a significant difference in overall survival was found for Karnofsky Performance Status (KPS $\leq 70: 122$ days; KPS > 70: 342 days), for RPA (recursive partitioning analysis) class (RPA class I: 1800 days; RPA class II: 281 days; RPA class III: 130 days), irradiated volume ( $\leq 2.5 \mathrm{ml}: 354$ days; > $2.5 \mathrm{ml}: 234$ days), prescribed dose ( $\leq 18$ Gy: 235 days; > 18 Gy: 351 days), gender (male: 235 days; female: 327 days) and whole brain radiotherapy (+WBRT: 341 days/-WBRT: 231 days). In multivariate analysis significance was confirmed for KPS, RPA class and gender. MRI and clinical symptoms suggested radiation necrosis in 21 patients after SRS +/- whole brain radiotherapy (WBRT). In five patients clinically relevant radiation necrosis was confirmed by PET imaging.

Conclusions: SRS alone or in combination with WBRT represents a feasible option as initial treatment for patients with brain metastases; however a significant subset of patients may develop neurological complications. Performance status, RPA class and gender were identified to predict improved survival in cerebral metastasized patients.

Keywords: Stereotactic radiotherapy, Cerebral metastases, Radiosurgery, Radiation necrosis

\section{Introduction}

Cerebral metastases are diagnosed in about $30 \%$ of patients with advanced tumors [1,2]. Lung cancer, breast cancer and malignant melanoma are the most common causes for brain metastases. Symptoms depend on localization and size including signs of increased intracranial

\footnotetext{
* Correspondence: claus.belka@med.uni-muenchen.de

${ }^{\dagger}$ Equal contributors

'Department of Radiation Oncology, University of Munich, Marchioninistr 15, Munich 81377, Germany

Full list of author information is available at the end of the article
}

pressure, headaches, vertigo, nausea and vomiting, paraesthesia and seizures.

Patients having more than three brain metastases are generally treated with whole-brain radiotherapy (WBRT). Oligometastatic patients with 1-3 lesions have a better prognosis and are therefore treated more aggressively. Beside neurosurgical resection stereotactic radiosurgery (SRS) is an effective treatment option for patients with 1-3 brain metastases [3,4]. For radiation treatment some studies have shown that SRS alone might be superior to WBRT alone for survival advantage of RPA class I patients $[5,6]$. It cannot be excluded that this effect is

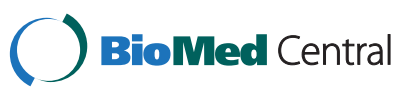

(c) 2014 Schüttrumpf et al.; licensee BioMed Central Ltd. This is an Open Access article distributed under the terms of the Creative Commons Attribution License (http://creativecommons.org/licenses/by/2.0), which permits unrestricted use, distribution, and reproduction in any medium, provided the original work is properly credited. The Creative Commons Public Domain Dedication waiver (http://creativecommons.org/publicdomain/zero/1.0/) applies to the data made available in this article, unless otherwise stated. 
partially caused by the available salvage options after radiosurgery.

In three randomized trials additional WBRT showed even better intracranial tumor control and reduced neurologic causes of death but failed to improve patients overall survival and functional independence [7-9]. The 1-year local control rates at the initial tumor site after neurosurgical resection or SRS +/- WBRT were about $80 \%[3,4,7,8]$. Intracranial relapse occurred more frequently in patients having received SRS or resection only. In this context WBRT was used more often as a salvage treatment. The deferred WBRT probably improved the length of the survival and functional independence in the observation arm. The latest Cochrane Analysis of WBRT reported an improved local and distant brain control but no difference in overall survival for SRS + WBRT compared to SRS alone [10].

SRS as well as WBRT has a risk for adverse events. Radiation necrosis appears 1-2 years after radiotherapy (RT) and cognitive decline develops over many years. For fractionated RT $(<2.5 \mathrm{~Gy} / \mathrm{d})$ high cumulative doses are tolerated. Radiation induced necrosis is predicted to occur in 5\% at a biologically effective dose of 120 Gy [11]. For SRS a correlation between the target volume, dose and the risk of adverse events has been demonstrated [12,13]. However the tolerated doses for SRS show a great range in literature. In dose escalation study RTOG 90-05 maximum tolerated doses were $24 \mathrm{~Gy}$, $18 \mathrm{~Gy}$, and 15 Gy for tumors $\leq 20 \mathrm{~mm}, 21-30 \mathrm{~mm}$, and 31-40 mm [14].

The present study was performed to assess factors that have prognostic relevance on survival in cerebral metastasized patients treated with stereotactic radiosurgery and to assess side effects with a special focus on radiation induced necrosis.

\section{Patients and methods}

Patient data and dose fractionation

Between March 2000 and December 2010340 patients with 1-3 cerebral metastases were treated with stereotactic radiosurgery.

Patients with stable systemic disease at the time of SRS or general cerebral progression during follow-up received additional WBRT. The prescribed dose for WBRT usually was $35 \mathrm{~Gy} / 37.5$ Gy in 14/15 fractions of $2.5 \mathrm{~Gy}$ or $30 \mathrm{~Gy}$ in 10 fractions of $3 \mathrm{~Gy}$ at midline, 5 fractions per week. Patients showing further single brain metastases during follow-up, but stable systemic disease, again were treated with SRS.

\section{Head frames}

For stereotactic radiosurgery a Brown-Robert-Wells (BRW) or Gill-Thomas-Cosman (GTC) stereotactic head frame was used. While the BRW frame is fixated to the head with four screws to ensure a definite connection between cranium and head frame the GTC frame is less invasive by using dental fixation. Afterwards a planning computed tomography $(\mathrm{CT})$ with localizer was performed. To ensure the correct position of the head frame a depth helmet was used to measure the distance between cranium and surface of the helmet. This control was done before planning $\mathrm{CT}$ and immediately before stereotactic radiosurgery.

\section{Radiation planning}

For radiation planning and image fusion Radionics Xknife ${ }^{\mathrm{mm}}$ was used. The gross tumor volume (GTV) was identified and delineated in fused image of the CT and the magnetic resonance imaging (MRI). Due to spherical growth of brain metastases the clinical target volume (CTV) was set equivalent to the GTV. Regarding risk structures and anatomical borders expansion of the GTV plus 1-2 mm resulted in the planning target volume (PTV).

\section{Dose}

Radiation dose was 24 Gy for metastases with a diameter $<20 \mathrm{~mm}, 18$ Gy for metastases between $20-30 \mathrm{~mm}$ and 15 Gy for a diameter $>30 \mathrm{~mm}$ prescribed to the $80 \%$ isodose. Due to the geometry of the metastases some patients received 20 Gy. A modified Linear Accelerator (Mevatron M/Fa. Siemens) with $6 \mathrm{MV}$ photons was used for treatment. The PTV was irradiated with three to eight arcs depending on size and localization.

\section{MRI protocol}

A T1 weighted contrast enhanced sequence was used to determine the gross tumor volume. No image tilt $\left(0^{\circ}\right)$ was allowed. Slice thickness $\leq 3 \mathrm{~mm}$, Inter-Slice-Spacing $0 \mathrm{~mm}$.

\section{FET-PET}

For PET scan the amino acid $\left[{ }^{18} \mathrm{~F}\right]$-fluoro-ethyl-L-tyrosine (FET) was used. FET uptake in the tissue was measured as standardized uptake value (SUV). Maximum lesion-to-brain ratios (LBRs) were calculated and timeactivity curves were analyzed.

\section{Statistics}

The patient data was collected between March 2000 and December 2010. All analyses were performed using the Statistical Package for Social Sciences (SPSS, Ver. 19.0, SPSS Inc, Chicago, IL). Survival analyses were based on Kaplan-Meier estimates, univariate testing was performed by means of the log-rank test and Cox regression analysis was used to determine hazard ratios as well as to perform a multivariate analysis. A two-tailed p-value $\leq$ 0.05 was considered significant. 


\section{Follow-up and assessment of radiation necrosis}

Follow-up was regularly performed every three months. If patients did not keep the appointments, a telephone follow-up was used. Cerebral staging was done by contrast enhanced MRI. If radiation necrosis was suspected, diagnostics was completed either by FET-PET and/or brain biopsy, or patients were treated with dexamethasone only ex juvantibus. Alternatively a control MRI was done about 4 weeks later.

\section{Results}

\section{Patient characteristics}

Between March 2000 and December 2010340 patients (159 males and 181 females) with newly diagnosed brain metastases were treated with SRS (Table 1). The median age was 62 years. One hundred ninety seven patients (57.9\%) had one metastasis, 101 patients (29.7\%) had two metastases and 31 patients $(9.1 \%)$ had three metastases. Some patients showing further single brain metastases but stable systemic disease during follow-up were again treated with SRS. Therefore eight patients had four metastases, two patients had five metastases and one patient even had seven metastases in total. The most common tumor types were lung cancer (55\%), malignant melanoma (14.4\%) and breast cancer (12.1\%). More than half of the patients $(55.6 \%)$ received no additional WBRT. Referring to the Radiation Therapy Oncology Group (RTOG) based recursive partitioning analysis (RPA) 26 patients $(7.7 \%)$ were RPA class I, 271 patients (79.7\%) RPA class II and 43 patients (12.6\%) RPA class III. Two hundred fifty eight patients (75.9\%) had a Karnofsky Performance Score $>70$.

\section{Survival data}

The median follow-up of all patients was 721 days using the reverse Kaplan-Meier [15]. The median survival time after SRS was 282 days; 1-year survival rate was $28.8 \%$ and 2-year survival rate was $10.6 \%$. Survival data after stereotactic radiosurgery of the cerebral metastases is shown in Table 2. Univariate analysis of potential prognostic factors showed a significant difference for Karnofsky Performance Status (KPS $\leq 70$ : 122 days; KPS $>70$ : 342 days; $\mathrm{p}<0.001$ ), for RPA (recursive partitioning analysis) class (RPA class I: 1800 days; RPA class II: 281 days; RPA class III: 130 days; $p<0.001$ ), irradiated volume $(\leq 2.5 \mathrm{ml}: 354$ days; $>2.5 \mathrm{ml}: 234$ days; $\mathrm{p}=$ 0.002 ), prescribed dose ( $\leq 18$ Gy: 235 days; > 18 Gy: 351 days; $\mathrm{p}<0.001$ ), gender (male: 235 days; female: 327 days; $\mathrm{p}=0.013)$ and whole brain radiotherapy (+WBRT: 341 days/-WBRT: 231 days; $\mathrm{p}=0.049)($ Figure 1$)$. For categorical analysis of volume and dose dependent overall survival the largest lesion in first irradiation session was used to categorize patients having more than one
Table 1 Baseline patient characteristics, $N=340$, WBRT - whole brain radiotherapy

\begin{tabular}{ll}
\hline Characteristic & Patients \\
\hline Median follow-up & 721 days \\
Sex & \\
- Male & $159(46.8 \%)$ \\
- Female & $181(53.2 \%)$ \\
Median age & 62 \\
Age & \\
- $<65$ y & $208(61.2 \%)$ \\
• $\geq 65$ y & $132(38.8 \%)$ \\
WBRT & \\
- No & $189(55.6 \%)$ \\
• Yes & $151(44.4 \%)$ \\
RPA class & \\
• I & $26(7.7 \%)$ \\
- II & $271(79.7 \%)$ \\
• III & $43(12.6 \%)$
\end{tabular}

Karnofsky Performance Score

$\cdot \leq 70$

$82(24.1 \%)$

$\cdot>70$

$258(75.9 \%)$

Number of cerebral metastases

$\cdot 1$

$197(57.9 \%)$

$\cdot 2$

$101(29.7 \%)$

$\cdot 3$

$31(9.1 \%)$

$\cdot 4$

$8(2.4 \%)$

$\cdot 5$

$2(0.6 \%)$

$1(0.3 \%)$

Histology

$\cdot$ NSCLC

$160(47.1 \%)$

- SCLC

$27(7.9 \%)$

- Malignant Melanoma $49(14.4 \%)$

- Breast Cancer $41(12.1 \%)$

- Renal Cell Carcinoma 20 (5.9\%)

- Others $43(12.6 \%)$

Median radiation volume $\quad 1.7 \mathrm{ml}$

Median dose to the $80 \%$ isodose 20 Gy

Radiation necrosis

- Yes

$21(6.2 \%)$

- No

319 (93.8\%)

metastasis (median volume $2.5 \mathrm{ml}$ and median dose $18 \mathrm{~Gy}$ for dominant lesion).

Multivariate analysis revealed the following factors to be statistically significant predictors for survival: the Karnofsky Performance Status (hazard ratio (HR) 2.19 for $K P S \leq 70$ vs. KPS $>70 ; \mathrm{p}<0.001$ ), RPA (HR 3.61 for 
Table 2 Univariate and multivariate analysis on potential prognostic factors for overall survival after stereotactic radiosurgery, ns - not significant, $\mathrm{Cl}$ - confidence interval

\begin{tabular}{|c|c|c|c|c|c|c|}
\hline \multirow[t]{2}{*}{ Factor } & \multirow{2}{*}{$\begin{array}{l}\text { Number } \\
\text { of patients }\end{array}$} & \multirow{2}{*}{$\begin{array}{l}\text { Median survival } \\
\text { time in days }\end{array}$} & \multicolumn{2}{|c|}{ Univariate analysis } & \multicolumn{2}{|l|}{ Multivariate analysis } \\
\hline & & & $95 \%-\mathrm{Cl}$ in days & $\begin{array}{l}\text { p-value } \\
\text { (unadjusted, log-rank) }\end{array}$ & $\begin{array}{l}\text { p-value } \\
\text { (adjusted, cox-regression) }\end{array}$ & Hazard ratio \\
\hline Sex & & & & 0.013 & 0.042 & 1.31 \\
\hline - Male & 159 & 235 & $172-298$ & & & \\
\hline - Female & 181 & 327 & $274-380$ & & & \\
\hline - Overall & 340 & 282 & $232-332$ & & & \\
\hline WBRT & & & & 0.049 & ns (0.067) & 1.28 \\
\hline • No & 189 & 231 & $172-290$ & & & \\
\hline - Yes & 151 & 341 & $280-402$ & & & \\
\hline - Overall & 340 & 282 & $232-332$ & & & \\
\hline KPS & & & & $<0.001$ & $<0.001$ & 2.19 \\
\hline$\cdot \leq 70$ & 82 & 122 & $84-160$ & & & \\
\hline$\cdot>70$ & 258 & 342 & $298-386$ & & & \\
\hline - Overall & 340 & 282 & $232-332$ & & & \\
\hline Histology & & & & ns (0.488) & & \\
\hline - NSCLC & 160 & 275 & $218-332$ & & & \\
\hline$\cdot \mathrm{SCLC}$ & 27 & 231 & $151-331$ & & & \\
\hline - Melanoma & 49 & 286 & $201-371$ & & & \\
\hline - Breast Ca & 41 & 383 & $153-613$ & & & \\
\hline$\cdot \operatorname{RCC}$ & 20 & 184 & $0-435$ & & & \\
\hline - Others & 43 & 265 & $36-582$ & & & \\
\hline - Overall & 340 & 282 & $217-494$ & & & \\
\hline Age & & & & ns $(0.1)$ & & \\
\hline$\cdot<65 y$ & 208 & 306 & $254-358$ & & & \\
\hline$\cdot \geq 65 y$ & 132 & 247 & $177-317$ & & & \\
\hline - Overall & 340 & 282 & $232-332$ & & & \\
\hline Number of metastases & & & & ns (0.764) & & \\
\hline$\cdot 1$ & 197 & 268 & $203-333$ & & & \\
\hline$\cdot 2$ & 101 & 275 & $183-367$ & & & \\
\hline$\cdot 3$ & 31 & 332 & $0-710$ & & & \\
\hline$\cdot 4$ & 8 & 467 & $47-905$ & & & \\
\hline$\cdot 5$ & 2 & 341 & - & & & \\
\hline$\cdot 7$ & 1 & 834 & - & & & \\
\hline - Overall & 340 & 282 & $232-332$ & & & \\
\hline Dose & & & & $<0.001$ & ns & \\
\hline$\cdot \leq 18 \mathrm{~Gy}$ & 175 & 235 & $156-314$ & & & \\
\hline$\cdot>18 \mathrm{~Gy}$ & 165 & 351 & $255-447$ & & & \\
\hline & 340 & 282 & $232-332$ & & & \\
\hline Volume & & & & 0.002 & ns & \\
\hline$\cdot \leq 2.5 \mathrm{ml}$ & 172 & 354 & $262-446$ & & & \\
\hline$\cdot>2.5 \mathrm{ml}$ & 168 & 234 & $162-306$ & & & \\
\hline - Overall & 340 & 282 & $232-332$ & & & \\
\hline
\end{tabular}


Table 2 Univariate and multivariate analysis on potential prognostic factors for overall survival after stereotactic radiosurgery, ns - not significant, $\mathbf{C l}$ - confidence interval (Continued)

\begin{tabular}{llllll}
\hline RPA class & & & $<0.001$ & $<0.001$ & \\
- I & 26 & 1800 & $362-3238$ & $<0.001$ & 3.61 \\
- II & 271 & 281 & $227-335$ & 0.001 & 3.85 \\
- III & 43 & 130 & $17-243$ & & \\
- Overall & 340 & 282 & & & \\
\hline
\end{tabular}

RPA II vs. I, HR 3.85 for RPA III vs. I; $\mathrm{p}<0.001$ for RPA I, $\mathrm{p}<0.001$ for RPA II, $\mathrm{p}=0.001$ for RPA III) and gender (HR 1.31 for male vs. female; $\mathrm{p}=0.042$ ) (Table 2).

\section{Analysis of radiation necrosis}

Radiation necrosis is regarded as the most relevant adverse event after SRS. During follow-up in 21 patients (6.2\%) radiation necrosis was supposed in MRI. The most common neurologic symptom was dizziness. Two patients had cerebellar ataxia. Eleven patients received FET-PET to differentiate between radiation necrosis und recurrent metastasis (Figure 2). The maximum lesionto-brain ratios (LBRs) were higher in patients with recurrent metastases $(n=6$; mean $L B R=2.55)$ than in patients with radiation necrosis $(n=5$; mean $L B R=1.84)$. Time-activity curves were assessed in nine patients with ten cerebral lesions. In five patients early peak of FET uptake followed by constant decline of uptake was seen (decreasing kinetics). These were all patients with high LBRs and were assumed to have recurrent metastasis. Four of these five patients had brain biopsy or neurosurgical resection. In two cases recurrent metastasis was confirmed histologically, the other patients had necrosis only. Dynamic evaluation of four patients with low LBRs showed constantly increasing FET uptake until the end of acquisition confirming radiation necrosis. Volume $(\mathrm{p}=0.151)$, prescribed dose $(\mathrm{p}=0.236)$ and fractionated WBRT $(\mathrm{p}=0.368)$ had no influence on radiation necrosis.

\section{Discussion}

The current study was performed to define prognostic factors for survival and the incidence of radiation necrosis in cerebral metastasized patients after treatment with stereotactic radiosurgery. The median overall survival was 282 days. Different prognostic factors could be identified including Karnofsky Performance Status, RPA class, irradiation volume, prescribed dose, gender and additional WBRT. Despite WBRT and gender these factors are well known to correlate with survival prognosis. RPA classes which were created as a prognostic tool are defined by age, KPS, presence of extracranial metastases and control of primary tumor. The overall survival of patients in the study cohort was 59.2 months for RPA class I, 9.2 months for RPA class II and 4.3 months for RPA class III. Compared to other historical groups the survival time, especially for RPA class I, is rather high. Sneed et al. reported a median survival time after SRS alone or SRS + WBRT of 14 and 15.2 months for RPA class I, 8.2 and 7 months for RPA class II and 5.3 and 5.5 for RPA class III [16]. In our study cohort only a few patients (7.6\%) met criteria for RPA class I and had more favorable features.

Male patients had a significantly shortened overall survival compared to females. This could be explained by the fact that fewer women smoke than men and breast cancer, which has better prognosis per se, occurred in women exclusively. Breast cancer as histologic entity had no significantly improved overall survival. This could be explained by the limited number of cases.

In categorical analysis high dose (>18 Gy) and small irradiation volume $(\leq 2.5 \mathrm{ml})$ correlated with prolonged survival. Both parameters might result in an increased local control rate with a decreased chance for neurological cause of death.

The univariate analysis of survival data suggested a significant survival benefit for patients that had received a whole-brain radiotherapy (SRS + WBRT: 341 days/SRS alone: 231 days; $\mathrm{p}=0.049$ ). Another retrospective analysis was associated with a trend towards improved survival for additional WBRT (median survival time 15.4 versus 8.3 months, $\mathrm{p}=0.08$ ) [17].

None of the prospective randomized studies could confirm these findings: Adding postoperative WBRT after surgical resection of single metastases prevented brain recurrence of tumor $(18 \%$ vs $70 \%, \mathrm{p}<0.001)$ and reduced neurologic cause of death $(14 \%$ vs $44 \%, \mathrm{p}=$ 0.003 ) compared to patients in the observation group. There was no significant difference between the 2 groups in overall length of survival or the length of time that patients remained functionally independent [9].

In another randomized trial from Japan 132 patients with 1 to 4 brain metastases where either treated with SRS + WBRT (65 patients) or with SRS alone (67 patients). The median survival time and 1-year survival rate were 8.0 months and $28 \%$ for the SRS group and 7.5 months and $39 \%$ for the SRS + WBRT group ( $\mathrm{p}=$ $0.42)$. The 1 -year local control rate $(73 \%$ vs. $89 \%, p=$ 

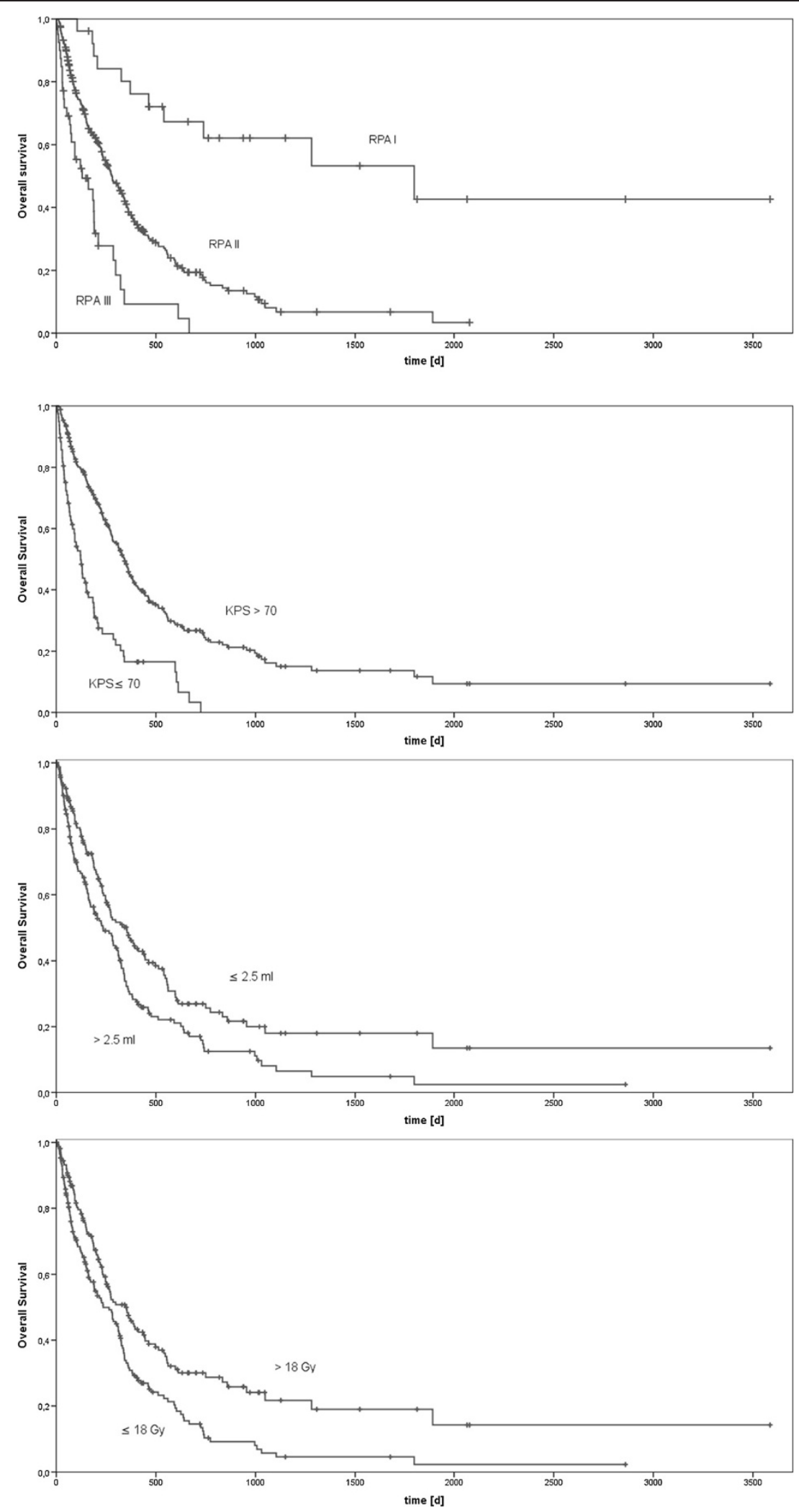

Figure 1 Kaplan-Meier analysis of overall survival for RPA classes $(p<0.001)$, KPS $(p<0.001)$, volume $(p=0.002)$ and dose $(p<0.001)$. 


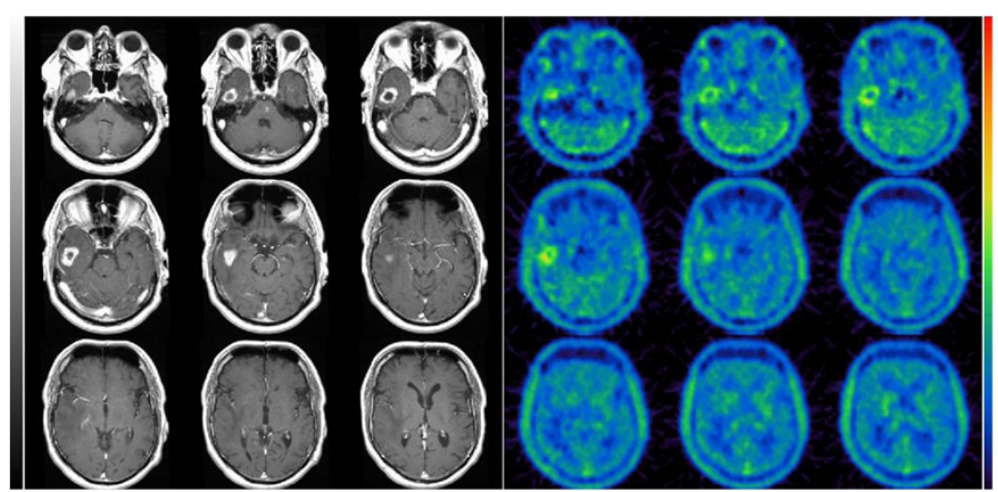

Figure 2 Example of recurrent brain metastasis: the study shows pathologic contrast enhancement on T1-weighted MRI and corresponding increased $\left[{ }^{18}\right.$ F]-FET uptake. While radiation necrosis was suspected in MRI, PET showed a pathologic FET uptake as seen in recurrent metastasis.

$0.003)$ and 1-year distant control rate (36\% vs. $58 \%, \mathrm{p}=$ 0.003) were better for the combined treatment [7].

The latest prospective trial with 359 patients was published in 2011 by Kocher et al. 199 patients received SRS, 160 patients were treated with surgical resection. After SRS, 100 patients were allocated to the observation group, 99 were allocated to WBRT. After surgery, 81 patients received WBRT while 79 patients had no further treatment. The median overall survival time, including surgical patients, was 10.7 months for the observation group and 10.9 for WBRT group $(\mathrm{p}=0.89)$. The 2-year local control rate $(69 \%$ vs. $81 \%, \mathrm{p}=0.04)$ and 2 -year distant control rate $(52 \%$ vs. $67 \%, \mathrm{p}=0.023)$ were improved by WBRT. Death caused by intracranial progression was $44 \%$ in the observation group and $28 \%$ in the WBRT group. Salvage therapies, e.g. WBRT, had to be used more frequently in the observation group [8]. Regarding the health-related quality-of-life no sustained decline in physical, role, and cognitive functioning were found. The latest randomized trial described transient changes in quality-of-life only [18].

In the retrospective analysis of the data base no difference was made between WBRT as an initial or salvage treatment. Given the fact that patients with favorable histology and stable extracranial disease were not distributed equally a selection bias cannot be excluded. Under these circumstances the survival benefit for WBRT has to be judged cautiously. Local control rates were not documented.

The most common late toxicity for SRS is radiation necrosis. In 21 patients (6.2\%) radiation necrosis after SRS was assumed in MRI. Radiation necrosis can be difficult to distinguish from tumor recurrence on MRI and may require the use of surgery, positron emission tomography (PET) or magnetic resonance spectroscopy (MRS). In patients having neurologic symptoms maximum SUV and dynamic evaluation of FET-PET confirmed radiation necrosis in five individuals. Additional
WBRT had no influence on the occurrence of radiation necrosis. Due to low incidence in the study no predictive factors for radiation necrosis were found. While the risk of radiation necrosis after conventional radiotherapy is highest in the first 2 years after treatment, appearance of radiation necrosis after SRS can be as short as 3 months [19]. In literature the incidence of brain necrosis varies from about $5-32 \%[7,8,13,20-22]$. Higher rate of necrosis occur with longer follow-up [14]. By using the pattern of time-activity curve in FET-PET local brain metastasis recurrence can be differentiated from radiation necrosis with high accuracy [23]. Radiation dose, tumor volume and radiation treatment planning factors are predictive for radiation induced necrosis [12,24,25]. In RTOG 90-05 study tumor volume $>8.2 \mathrm{ml}$ and a ratio of maximum dose to prescription dose $>2$ were significantly associated with unacceptable toxicity [26]. The only predictive parameter influencing the risk of radiation necrosis described by Valery et al. was the conformity index [27].

\section{Conclusions}

SRS alone or in combination with WBRT is an effective treatment for patients with 1-3 cerebral metastases; however a small subset of patients may develop neurological complications. KPS and RPA class are relevant prognostic factors for overall survival. Especially for patients with favorable features additional WBRT should be considered without having increased rates of necrosis.

\section{Consent}

Written informed consent was obtained from the patient for the publication of this report and accompanying images.

\section{Abbreviations}

BG: Background; FET: $\left[{ }^{18}\right.$ F]-fluoro-ethyl-L-tyrosine; HR: Hazard ratio; Ns: Not significant; NSCLC: Non-small-cell lung cancer; KPS: Karnofsky performance status; MM: Malignant melanoma; MRI: Magnetic resonance imaging; 
PET: Positron emission tomography; PTV: Planning target volume; RCC: Renal cell cancer; RPA: Recursive partitioning analysis; SCLC: Small-cell lung cancer; SRS: Stereotactic radiosurgery; SUVmax: Maximum standardized uptake value; vs: Versus; WBRT: Whole brain radiotherapy.

\section{Competing interests}

The authors declare that they have no competing interests.

\section{Authors' contributions}

LHS collected patient data and wrote the manuscript. MN performed associated statistics, designed the protocol and critically revised the manuscript. AS built the departmental database and collected patient data. $\mathrm{NJ}$ analyzed FET-PET. SBN, AS and FM critically revised the manuscript, too. $\mathrm{CB}$ provided the idea and conception and took part in the preparation of the manuscript. All authors read and approved the final manuscript.

\section{Author details}

'Department of Radiation Oncology, University of Munich, Marchioninistr 15, Munich 81377, Germany. ${ }^{2}$ Department of Nuclear Medicine, University of Munich, Marchioninistr 15, Munich 81377, Germany. ${ }^{3}$ Gemeinschaftspraxis für Strahlentherapie und Radioonkologie am Klinikum Schwabing, Kölner Platz 1, Munich 80804, Germany.

\section{Received: 26 November 2013 Accepted: 22 April 2014}

Published: 2 May 2014

\section{References}

1. Khuntia D, Brown P, Li J, Mehta MP: Whole-brain radiotherapy in the management of brain metastasis. J Clin Oncol 2006, 24(8):1295-1304

2. Meisner J, Meyer A, Polivka B, Karstens JH, Bremer M: Outcome of moderately dosed radiosurgery for limited brain metastases: report of a single-center experience. Strahlenther Onkol 2010, 186(2):76-81.

3. D'Agostino GR, Autorino R, Pompucci A, De Santis MC, Manfrida S, Di Lella G, Mantini G, Frascino V, Chiesa S, Albanese A, Dinapoli N, Azario L, Fiorentino A, Valentini V, Anile C, Balducci M: Whole-brain radiotherapy combined with surgery or stereotactic radiotherapy in patients with brain oligometastases: long-term analysis. Strahlenther Onkol 2011, 187(7):421-425.

4. Auchter RM, Lamond JP, Alexander E, Buatti JM, Chappell R, Friedman WA, Kinsella TJ, Levin AB, Noyes WR, Schultz CJ, Loeffler JS, Mehta MP: A multiinstitutional outcome and prognostic factor analysis of radiosurgery for resectable single brain metastasis. Int J Radiat Oncol Biol Phys 1996, 35(1):27-35.

5. Kocher M, Maarouf M, Bendel M, Voges J, Muller RP, Sturm V: Linac radiosurgery versus whole brain radiotherapy for brain metastases: a survival comparison based on the RTOG recursive partitioning analysis. Strahlenther Onkol 2004, 180(5):263-267.

6. Rades D, Pluemer A, Veninga T, Hanssens P, Dunst J, Schild SE: Whole-brain radiotherapy versus stereotactic radiosurgery for patients in recursive partitioning analysis classes 1 and 2 with 1 to 3 brain metastases. Cancer 2007, 110(10):2285-2292

7. Aoyama H, Shirato H, Tago M, Nakagawa K, Toyoda T, Hatano K, Kenjyo M, Oya N, Hirota S, Shioura H, Kunieda E, Inomata T, Hayakawa K, Katoh N, Kobashi G: Stereotactic radiosurgery plus whole-brain radiation therapy vs stereotactic radiosurgery alone for treatment of brain metastases: a randomized controlled trial. JAMA 2006, 295(21):2483-2491.

8. Kocher M, Soffietti R, Abacioglu U, Villa S, Fauchon F, Baumert BG, Fariselli L, Tzuk-Shina T, Kortmann RD, Carrie C, Ben Hassel M, Kouri M, Valeinis E, van den Berge D, Collette S, Collette L, Mueller RP: Adjuvant whole-brain radiotherapy versus observation after radiosurgery or surgical resection of one to three cerebral metastases: results of the EORTC 22952-26001 study. J Clin Oncol 2011, 29(2):134-141.

9. Patchell RA, Tibbs PA, Regine WF, Dempsey RJ, Mohiuddin M, Kryscio RJ, Markesbery WR, Foon KA, Young B: Postoperative radiotherapy in the treatment of single metastases to the brain: a randomized trial. JAMA 1998, 280(17):1485-1489.

10. Tsao MN, Lloyd N, Wong RK, Chow E, Rakovitch E, Laperriere N, Xu W, Sahgal A: Whole brain radiotherapy for the treatment of newly diagnosed multiple brain metastases. Cochrane Database Syst Rev 2012, 4, CD003869.

11. Lawrence YR, Li XA, el Naqa I, Hahn CA, Marks LB, Merchant TE, Dicker AP: Radiation dose-volume effects in the brain. Int J Radiat Oncol Biol Phys 2010, 76(3 Suppl):S20-S27.
12. Blonigen BJ, Steinmetz RD, Levin L, Lamba MA, Warnick RE, Breneman JC: Irradiated volume as a predictor of brain radionecrosis after linear accelerator stereotactic radiosurgery. Int I Radiat Oncol Biol Phys 2010, 77(4):996-1001.

13. Minniti G, Clarke E, Lanzetta G, Osti MF, Trasimeni G, Bozzao A, Romano A, Enrici RM: Stereotactic radiosurgery for brain metastases: analysis of outcome and risk of brain radionecrosis. Radiat Oncol 2011, 6:48

14. Shaw E, Scott C, Souhami L, Dinapoli R, Kline R, Loeffler J, Farnan N: Single dose radiosurgical treatment of recurrent previously irradiated primary brain tumors and brain metastases: final report of RTOG protocol 90-05. Int J Radiat Oncol Biol Phys 2000, 47(2):291-298.

15. Altman DG, De Stavola BL, Love SB, Stepniewska KA: Review of survival analyses published in cancer journals. Br J Cancer 1995, 72(2):511-518.

16. Sneed PK, Suh JH, Goetsch SJ, Sanghavi SN, Chappell R, Buatti JM, Regine WF, Weltman E, King VJ, Breneman JC, Sperduto PW, Mehta MP: A multiinstitutional review of radiosurgery alone vs. radiosurgery with whole brain radiotherapy as the initial management of brain metastases. Int $\mathrm{J}$ Radiat Oncol Biol Phys 2002, 53(3):519-526.

17. Pirzkall A, Debus J, Lohr F, Fuss M, Rhein B, Engenhart-Cabillic R, Wannenmacher M: Radiosurgery alone or in combination with wholebrain radiotherapy for brain metastases. J Clin Oncol 1998, 16(11):3563-3569.

18. Soffietti R, Kocher M, Abacioglu UM, Villa S, Fauchon F, Baumert BG, Fariselli L, Tzuk-Shina T, Kortmann RD, Carrie C, Ben Hassel M, Kouri M, Valeinis E, van den Berge D, Mueller RP, Tridello G, Collette L, Bottomley A: A European organisation for research and treatment of cancer phase III trial of adjuvant whole-brain radiotherapy versus observation in patients with one to three brain metastases from solid tumors after surgical resection or radiosurgery: quality-of-life results. J Clin Oncol 2013, 31(1):65-72.

19. Soussain C, Ricard D, Fike JR, Mazeron JJ, Psimaras D, Delattre JY: CNS complications of radiotherapy and chemotherapy. Lancet 2009, 374(9701):1639-1651.

20. Frazier IL, Batra S, Kapor S, Vellimana A, Gandhi R, Carson KA, Shokek O, Lim $M$, Kleinberg L, Rigamonti D: Stereotactic radiosurgery in the management of brain metastases: an institutional retrospective analysis of survival. Int J Radiat Oncol Biol Phys 2010, 76(5):1486-1492.

21. Williams BJ, Suki D, Fox BD, Pelloski CE, Maldaun MV, Sawaya RE, Lang FF, Rao G: Stereotactic radiosurgery for metastatic brain tumors: a comprehensive review of complications. J Neurosurg 2009, 111(3):439-448.

22. Lutterbach J, Cyron D, Henne K, Ostertag CB: Radiosurgery followed by planned observation in patients with one to three brain metastases. Neurosurgery 2003, 52(5):1066-1073. discussion 1073-1064.

23. Galldiks N, Stoffels G, Filss CP, Piroth MD, Sabel M, Ruge MI, Herzog H, Shah $\mathrm{NJ}$, Fink GR, Coenen HH, Langen K: Role of O-(2-(18)F-fluoroethyl)-L-tyrosine PET for differentiation of local recurrent brain metastasis from radiation necrosis. J Nucl Med 2012, 53(9):1367-1374.

24. Voges J, Treuer H, Sturm V, Buchner C, Lehrke R, Kocher M, Staar S, Kuchta J, Muller RP: Risk analysis of linear accelerator radiosurgery. Int J Radiat Oncol Biol Phys 1996, 36(5):1055-1063

25. Korytko T, Radivoyevitch T, Colussi V, Wessels BW, Pillai K, Maciunas RJ, Einstein DB: 12 Gy gamma knife radiosurgical volume is a predictor for radiation necrosis in non-AVM intracranial tumors. Int I Radiat Oncol Biol Phys 2006, 64(2):419-424

26. Shaw E, Scott C, Souhami L, Dinapoli R, Bahary JP, Kline R, Wharam M, Schultz C, Davey P, Loeffler J, Del Rowe J, Marks L, Fisher B, Shin K: Radiosurgery for the treatment of previously irradiated recurrent primary brain tumors and brain metastases: initial report of radiation therapy oncology group protocol (90-05). Int J Radiat Oncol Biol Phys 1996, 34(3):647-654

27. Valery CA, Cornu P, Noel G, Duyme M, Boisserie G, Sakka LJ, Mazeron JJ, van Effenterre R: Predictive factors of radiation necrosis after radiosurgery for cerebral metastases. Stereotact Funct Neurosurg 2003, 81(1-4):115-119.

\section{doi:10.1186/1748-717X-9-105}

Cite this article as: Schüttrumpf et al:: Prognostic factors for survival and radiation necrosis after stereotactic radiosurgery alone or in combination with whole brain radiation therapy for 1-3 cerebral metastases. Radiation Oncology 2014 9:105. 